\title{
Herstelrecht in de gevangenis: een achterhaalde paradox?
}

\author{
Helene De Vos
}

Tünde Barabás, Borbála Fellegi en Szandra Windt (eds.) (2012). Responsibility-taking, Relationship-building and Restoration in Prisons. Mediation and Restorative Justice in Prison Settings, Budapest, P-T Mühely, commissioned by the National Institute of Criminology, $327 p$.

Zoals de veelbelovende titel van bovengenoemd verzamelwerk doet vermoeden, is het Europese project dat aan de basis van dit werk ligt zowel qua inhoud als qua opzet erg ambitieus. ${ }^{1}$ Vijf hoofdstukken met bijdragen van in totaal vijftien auteurs uit vier Europese landen geven een genuanceerd beeld van de mogelijkheden om herstelrechtelijke praktijken toe te passen tijdens de uitvoering van de gevangenisstraf. Hoewel deze praktijken een grote meerwaarde kunnen bieden voor de betrokken partijen, wordt duidelijk dat de gevangeniscontext de toepassing ervan erg bemoeilijkt. Terecht waarschuwen de auteurs dan ook voor twee grote risico's: de fundamentele herstelrechtelijke principes mogen niet afgezwakt worden om de toepassing ervan binnen de gevangenis te vergemakkelijken, en - misschien nog belangrijker - herstelrecht mag niet beschouwd worden als nieuwe legitimatie voor de gevangenisstraf. Daarom kan dit verzamelwerk best gelezen worden met de concluderende boodschap van Ivo Aertsen (hoofdstuk 4, p. 276) in het achterhoofd: herstelrecht binnen de gevangenis is slechts geloofwaardig als dit ook tot uiting komt in het ruimere strafrechtelijk beleid, wat in de eerste plaats een verminderd gebruik van de gevangenisstraf impliceert.

De eerste vier hoofdstukken van het verzamelwerk bekijken de toepassing van herstelrechtelijke principes en praktijken tijdens de gevangenisstraf telkens vanuit een ander nationaal perspectief. Concreet levert dit achtereenvolgens een Hongaars, Engels, Duits en Belgisch hoofdstuk op. Niettemin overschrijdt de relevantie van elk hoofdstuk deze nationale grenzen. Het eerste hoofdstuk bespreekt de drie delen van het onderzoek dat in Hongarije plaatsvond, maar is - nogal artificieel - opgedeeld in vier bijdragen. In de eerste bijdrage van dit Hongaarse hoofdstuk beschrijft Tünde Barabás een deel van de resultaten van het onderzoek naar de attituden van gedetineerden, slachtoffers, het gevangenispersoneel en het gevangenismanagement ten aanzien van bemiddeling en hun bereidheid om eraan deel te nemen. Meer concreet gaat deze bijdrage over de houding van minderjarige en meerderjarige gedetineerden, zoals die naar voren komt uit 200 vragenlijsten, 100 diepte-interviews en 8 focusgroepen. Ondanks de enorm rijke data 
die de combinatie van deze drie dataverzamelingsmethoden ongetwijfeld heeft opgeleverd, is de rapportering ervan teleurstellend. De diepgang van de kwalitatieve data gaat immers verloren doordat de resultaten van de diepte-interviews en vragenlijsten samen besproken worden. De resultaten van de focusgroepen worden dan weer wel met meer diepgang weergegeven. Hoewel $64 \%$ van de bevraagde gedetineerden bereid is om zijn slachtoffer te ontmoeten en de schade te vergoeden, leiden de onderzoekers uit de interviews en focusgroepen af dat een groot deel van hen toch niet geschikt is om effectief aan bemiddeling deel te nemen. Ze stellen immers vast dat 'the majority of inmates are unable to go beyond their egocentrism' (Tünde Barabás, hoofdstuk 1, p. 58). Daarnaast zouden de problematische geestelijke gezondheid en de beperkte intellectuele capaciteiten de deelname voor een groot aantal gedetineerden belemmeren.

Lezers die zich afvragen op welke wijze de dataverzameling precies gebeurde, vinden het antwoord in de tweede bijdrage. Naast de methodologie bespreekt Szandra Windt de overige resultaten van het voorbereidende attitudeonderzoek. Vooral het management blijkt grote voorstander te zijn van de toepassing van bemiddeling in de gevangenis. Het bewakend personeel vreest daarentegen dat bemiddeling de normale werking van de gevangenis zou verstoren en de gecontacteerde slachtoffers, ten slotte, toonden wel interesse, maar zouden er zelf niet meteen aan deelnemen. In tegenstelling tot de resultaten over het management en het bewakend personeel, worden de resultaten over de slachtoffers nauwelijks toegelicht. Hierdoor blijven de redenen voor hun terughoudendheid onduidelijk. Vervolgens lichten Dóra Szegő en Borbála Fellegi in de derde bijdrage hun pilootproject toe dat voortbouwt op het attitudeonderzoek. Een jaar lang werden in twee Hongaarse gevangenissen herstelrechtelijke praktijken aangewend met drie doelen: om celconflicten op te lossen, om familiebanden te verbeteren en om in dialoog met het slachtoffer tot herstel te komen. De resultaten van dit pilootproject benadrukken enerzijds de invloed van de strikte regels en de hiërarchische, bureaucratische organisatie van de gevangenis en anderzijds de verschillende perspectieven van het bewakend personeel, de betrokken bemiddelaars, de onderzoekers en de gedetineerden. András Szúcs eindigt het Hongaarse hoofdstuk met de vierde bijdrage waarin hij reflecteert over de wettelijke mogelijkheden van bemiddeling tijdens de strafuitvoering. Hij pleit ervoor om de toekenning van probatie te vervroegen indien gedetineerden met hun slachtoffer een herstelgerichte overeenkomst hebben bereikt. Hij lijkt hierbij echter te vergeten dat gedetineerden die aan bemiddeling deelnemen met het oog op een vervroegde invrijheidstelling, in de eerste bijdrage van dit hoofdstuk worden bestempeld als egocentrisch en ongeschikt voor bemiddeling. Het is daarom paradoxaal om een succesvolle bemiddeling te belonen met een vervroegde invrijheidstelling.

Het tweede hoofdstuk door Theo Gavrielides belicht de toepassing van herstelrechtelijke praktijken in jeugdinstellingen vanuit Engels perspectief. Interessant is dat dit hoofdstuk zowel geografisch als inhoudelijk verder reikt dan de Engelse jeugdinstellingen. Zo geeft het een - enigszins verouderd - internationaal overzicht van bestaande herstelrechtelijke projecten in gevangenissen en stelt het een nieuwe classificatie voor: een tweedeling tussen de programma's die direct op herstel gericht zijn en de activiteiten ter voorbereiding van deze programma's, die 
dus eerder indirect op herstel gericht zijn. Het empirisch onderzoek, bestaande uit diepte-interviews met jeugddelinquenten en experts en observaties in een jeugdinstelling, wijst erop dat herstelrecht tegemoet kan komen aan de specifieke noden van jeugddelinquenten. Bij de implementatie van herstelrechtelijke praktijken binnen een jeugdinstelling zou wel het risico bestaan dat de fundamentele herstelrechtelijke waarden om praktische redenen naar de achtergrond verdwijnen. De auteur somt in deze context 35 moeilijkheden op bij de toepassing van herstelrecht tijdens de strafuitvoering, gaande van gebrekkige financiële middelen tot de tegenstrijdige ideologische doelstellingen van herstelrecht en de gevangenisstraf. Hoewel een aantal van de moeilijkheden van deze enorme lijst toch fundamentele belemmeringen lijken te vormen, wijzen de bestaande succesverhalen er volgens hem op dat deze uitdagingen niet onoverkomelijk zijn.

Het derde hoofdstuk vertrekt van de vaststelling dat herstelrecht, op enkele pilootprojecten na, niet wordt toegepast in de Duitse gevangenissen, hoewel de doelstellingen ervan grotendeels samenvallen met die van de gevangenisstraf. Zowel herstelrecht als gevangenisstraf beoogt in Duitsland immers rehabilitatie en herstel. Deze vaststelling bracht de auteurs Arthur Hartmann, Marie Haas, Felix Steengrafe, Judith Geyer en Tim Steudel ertoe om 459 vragenlijsten af te nemen bij het Duitse gevangenispersoneel over hun kennis over en hun houding ten aanzien van slachtoffer-daderbemiddeling, Family Group Conferencing en Circles. Een reeks taart- en staafdiagrammen geeft overzichtelijk weer in welke mate het gevangenispersoneel vertrouwd is met de genoemde herstelrechtelijke praktijken en er al dan niet voorstander van is. Daarnaast pasten de auteurs slachtoffer-daderbemiddeling toe in de jeugdgevangenis van Oslebhausen, waaraan 27 daders en 7 slachtoffers deelnamen. De auteurs evalueerden dit project door de deelnemers achteraf te interviewen. Deze evaluatie wordt geïllustreerd aan de hand van citaten uit één interview. Deze citaten drukken de erg positieve ervaring van het slachtoffer met de bemiddeling uit. Door deze positieve ervaring van één slachtoffer zo in de verf te zetten, lijken de auteurs liever het succes van de bemiddeling te willen benadrukken dan de vele moeilijkheden die ze eerder in het hoofdstuk moesten erkennen.

In het vierde hoofdstuk beschrijft Ivo Aertsen de wijze waarop herstelrecht in de late jaren negentig ingang vond in de Belgische gevangenissen door de introductie van herstelconsulenten. Hij legt hierbij duidelijk de link tussen principes van herstelrecht en de ideeën achter de strafuitvoering, zoals die tot uiting komen in de Basiswet van 12 januari 2005 betreffende het gevangeniswezen en de rechtspositie van de gedetineerden en de Wet van 17 mei 2006 betreffende de externe rechtspositie van veroordeelden tot een vrijheidsstraf en de aan het slachtoffer toegekende rechten in het raam van de strafuitvoeringsmodaliteiten. Hoewel herstelgerichte detentie voor hem een logisch gevolg is van de idee dat herstel het hoofddoel van het strafrecht zou moeten zijn, waarschuwt hij dat hier minstens twee risico's aan zijn verbonden. Ten eerste lijken de doelstellingen van herstelrecht en van de vrijheidsstraf tegengesteld: inclusie en re-integratie tegenover exclusie en stigmatisering. Ten tweede bestaat volgens hem het gevaar dat herstelrecht gezien wordt als nieuwe legitimatie voor de gevangenisstraf. Hoewel deze waarschuwingen voor het hele verzamelwerk gelden - en bovendien erkend worden door de andere auteurs - 
wordt in de andere hoofdstukken nauwelijks gereflecteerd over de mogelijke gevolgen van de introductie van herstelrecht voor de gevangenis en haar legitimatie. In een verzamelwerk over herstelrecht dat het bestaan van de gevangenis expliciet als gegeven beschouwt, kon dat nochtans verwacht worden. Aertsen vervolgt zijn hoofdstuk met zes andere fundamentele uitdagingen voor herstelgerichte detentie, waarbij hij onder meer waarschuwt voor het risico dat de middelen die initieel werden vrijgemaakt voor herstelrecht na verloop van tijd nieuwe doelen kunnen gaan dienen, zoals dat in België het geval was bij de afschaffing van de functie van herstelconsulent in 2008.

$\mathrm{Na}$ de 'nationale' hoofdstukken behandelt het vijfde en laatste hoofdstuk een Belgische en twee Hongaarse casestudies. Alle drie zijn het succesverhalen over de toepassing van herstelrechtelijke praktijken tijdens de gevangenisstraf, waarbij de dader veroordeeld is voor moord. Vooral bij de eerste casestudy, geschreven door Els Goossens, kom je als lezer heel dicht bij dader en slachtoffer te staan, doordat de persoonlijke vragen en bezorgdheden van dader en slachtoffer geschetst worden. Dit verhaal wordt aangevuld met meer algemene aspecten van bemiddeling, waardoor een concreet beeld ontstaat van de wijze waarop bemiddeling in België wordt georganiseerd. Hierdoor worden ook de directe implicaties van de specifieke gevangeniscontext duidelijk. Hoewel de twee Hongaarse casussen de lezer iets minder dicht bij de dader en zijn omgeving brengen, geven ook deze bijdragen een heel concreet beeld van de waarde van herstelrechtelijke praktijken tijdens de uitvoering van de gevangenisstraf. Het feel good-einde van dit verzamelwerk laat de lezer in het licht van de voorgaande hoofdstukken echter wel met vragen zitten, bijvoorbeeld hoe representatief zijn dergelijke succesverhalen?

De combinatie van de casussen met concrete resultaten uit empirisch onderzoek en theoretische reflecties maakt dit verzamelwerk erg waardevol voor zowel onderzoekers als beleids- en praktijkmensen. De internationale dimensie van het werk draagt hier nog toe bij. Het lezen van het verzamelwerk wordt evenwel bemoeilijkt door de beperkte samenhang ervan. Het gebrek aan algemene conclusie enerzijds en aan volledige en coherente toelichting van de onderzoeksopzet anderzijds geeft de indruk dat er weinig moeite is gedaan om de vijf hoofdstukken tot een geheel te verwerken.

Bovendien maakt de onlogische opbouw het niet altijd gemakkelijk om de rode draad te blijven zien. De afbeelding op de kaft van het verzamelwerk kan dan ook als tip voor de lezer gezien worden. De laatste stukjes van de afgebeelde puzzel - waarop Michelangelo's schilderij 'De schepping van Adam' te zien is - moeten nog op de juiste plaats gelegd worden. Dit geldt ook voor bepaalde bijdragen van het verzamelwerk: hoewel het geheel een genuanceerd beeld schetst van de mogelijkheden om herstelrecht toe te passen tijdens de strafuitvoering en hoewel de logica van de redacteurs - na het hele boek te hebben gelezen - begrijpelijk is, zou het werk beter tot zijn recht komen wanneer de hoofdstukken in een andere volgorde gelezen worden. Beter is het wellicht om na het voorwoord eerst het hoofdstuk van Ivo Aertsen te lezen om inzicht te krijgen in de fundamentele principes van herstelrecht. Hij begint zijn hoofdstuk met een aantal achterliggende spanningsvelden die eigenlijk in het begin van dit verzamelwerk hadden moeten staan. Vervolgens past het te beginnen aan de casestudies, die een heel concreet 
beeld geven van waar het in de praktijk precies over gaat. Nadien volgt dan het hoofdstuk over Engeland waarin een overzicht wordt gegeven over de wereldwijd gedocumenteerde herstelrechtelijke projecten in gevangenissen, met daarna het hoofdstuk over Duitsland en ten slotte het hoofdstuk over Hongarije. Eigenlijk is het hoofdstuk over Hongarije exemplarisch voor deze onlogische volgorde: de vier delen van dit Hongaarse hoofdstuk behandelen hetzelfde empirisch onderzoek maar, zoals gezegd, wordt de onderzoeksopzet pas in het tweede deel duidelijk. Het is daarom logischer om eerst dit tweede deel te lezen en dan pas het eerste deel.

\section{Herstelrecht en gevangenisstraf: geen tegenstelling in theorie, wel in praktijk?}

Heel het verzamelwerk is opgebouwd rond de paradox tussen herstelrecht en de uitvoering van de gevangenisstraf. Deze schijnbare tegenstelling wordt in het voorwoord geilllustreerd door te stellen dat de gevangenisstraf op de dader gericht is als reactie op het misdrijf dat hij in het verleden pleegde, terwijl herstelrecht zich net op de toekomst richt, met het oog op een betere toekomst voor dader en slachtoffer. Doorheen de verschillende hoofdstukken komt deze tegenstelling tussen herstelrecht en gevangenisstraf naar voren in concepten als vrijwilligheid versus dwang of inclusie versus uitsluiting en stigmatisering. Op theoretisch niveau lijken deze tegenstellingen gemakkelijk te overbruggen. Zo blijken de officiële doelen van de gevangenisstraf in bepaalde landen zoals Duitsland en België zelfs dezelfde te zijn als die van herstelrecht: herstel, rehabilitatie en re-integratie. Voor Theo Gavrielides hoeven we niet eens naar deze strafdoelen te kijken om een gemeenschappelijk doel te vinden. Bij de toelichting van zijn benadering van herstelrecht als 'restorative punishment' legt hij namelijk uit dat afschrikking een gunstig neveneffect is van deze herstelrechtelijke bestraffing. Hij beschouwt afschrikking daardoor als gemeenschappelijke doelstelling van de gevangenisstraf en herstelrecht.

Theoretisch valt deze kloof tussen de gevangenisstraf en herstelrecht dus wel te overbruggen, maar in de praktijk, zo toont dit boek, blijkt de gevangeniscontext de toepassing van de herstelrechtelijke praktijken toch erg te bemoeilijken. De paradox tussen de gevangenisstraf en herstelrecht moet daarom misschien niet zozeer vanuit theoretisch perspectief bekeken worden - hoewel dit natuurlijk een eerste stap is - maar wel vanuit praktisch perspectief, waarbij de invloed van het gevangenisleven op de veroordeelden fundamenteel is en geen loutere achtergrondinformatie. Er wordt in verschillende hoofdstukken wel verwezen naar cijfermateriaal over het gebruik van de gevangenisstraf en de gevangenispopulatie en naar een aantal kenmerkende contextfactoren zoals de bureaucratische en hiërarchische structuur, de overbevolking, het geweld en het gebrek aan middelen, de verveling en het gebrek aan autonomie, maar deze informatie blijft beperkt tot inleidende achtergrondinformatie. Nochtans stelden Dóra Szegő en Borbála Fellegi op basis van hun Hongaarse pilootstudie vast dat 
'(...) all factors that served to move inmates out of their prison community roles were conditions that supported the introduction of restorative practices. This includes stepping out of their status in the informal prison hierarchy, their communication strategies and ongoing conflicts.' (Dóra Szegő en Borbála Fellegi, hoofdstuk 1, p. 116)

In dit opzicht is het enigszins verrassend te noemen dat in het werk nauwelijks gewezen wordt op de nochtans uitgebreide - en in deze optiek uiterst relevante gevangenissociologische literatuur. Uitzonderingen zijn Martin Wright, die in het voorwoord over 'institutionalization' spreekt, en Ivo Aertsen, die verwijst naar Donald Clemmers concept 'prisonization', waarmee het proces wordt aangeduid waarbij gedetineerden zich de gebruiken, gewoonten en algemene cultuur van de gevangenis in meer of mindere mate eigen maken (Clemmer, 1958). Naast de begrippen institutionalization en prisonization verwijzen de klassieke gevangenissociologische werken ook naar de mortification of the self, waarbij gedetineerden hun bestaande zelfperceptie verliezen ten gevolge van een hele reeks vernederingen die ze ondergaan (Goffman, 1961) en de pains of imprisonment (Sykes, 1958) om de schadelijke gevolgen van de vrijheidsstraf te duiden. Meer recent wijzen onderzoekers op nieuwe pijnen van de vrijheidsberoving, zoals de verveling, het gebrek aan communicatie, de angst voor het onbekende en later voor de vrijlating, de onderwerping aan psychologische tests, individuele verantwoordelijkheid en verwarring (Crewe, 2011; Jones, 2007; Shammes, 2014).

In deze context lijkt het voor gedetineerden moeilijk om zich oprecht op herstel te richten, zelfs al zijn de officiële doelstellingen van de gevangenisstraf reintegratie, rehabilitatie en herstel. Hoewel dit werk een ambitieuze en omvattende poging heeft gedaan om herstelrechtelijke toepassingen in de gevangenis te duiden en de moeilijkheden ervan erkent, hangt het misschien een iets te rooskleurig beeld op door de nadruk te leggen op de succesverhalen. We kunnen daarom besluiten met Gavrielides' waarschuwing dat ' $R J$ might not be a bed-time story any more, but is not a panacea for all the deficiencies of the current criminal justice system either' (Gavrielides, 2007: 9, in hoofdstuk 2, p. 165).

\section{Bibliografie}

Clemmer, D. (1958). The Prison Community. New York: Holt, Rinehart and Winston.

Crewe, B. (2011). Depth, weight, tightness: Revisiting the pains of imprisonment, European Journal of Criminology, 8, 455-468.

Goffman, E. (1961). Asylums. Essays on the Social Situation of Mental Patients and Other Inmates. Harmondsworth: Penguin Books Ltd.

Jones, H.L. (2007). The Pains of Custody: how Young Men Cope through the Criminal Justice System. Hull: Department of Social Sciences, University of Hull.

Shammas, V.L. (2014). The pains of freedom: Assessing the ambiguity of Scandinavian penal exceptionalism on Norway's Prison Island, Punishment \& Society, 16, 104-123.

Sykes, G. (1958). The Society of Captives. New Jersey: Princeton University Press. 